\title{
The Prevalence of Urinary Incontinence and its Impact on Quality of Life among the University Female Staff in South Africa
}

\begin{abstract}
Background: Urinary incontinence (UI) is a common problem among females and has been associated with significant decreased quality of life. Few women seek help for this condition with only a few who consult physiotherapy treatment.

Purpose: To determine the prevalence of urinary incontinence and its impact on quality of life among the university women in South Africa.

Method: A quantitative cross-sectional study design with 145 women randomly selected from the university. A questionnaire was used to determine UI Diagnosis; Impact on QOL and treatment seeking tendencies. BMI was measured objectively. Ethical clearance was obtained from University. Data was analysed using SPSS 17.0

Results: Forty six(32\%) women reported to having UI. Risk factors associated with UI included age, race, and obesity. UI had a significant negative impact on quality of life and only $4.4 \%$ of participants with UI consulted physiotherapy for this condition.

Conclusion: There is a high prevalence of UI among the women at this university with a significant impact on quality of life.The role of Physiotherapy in management of UI has been demonstrated and there is therefore a need to empower women with non-invasive treatment options, like physiotherapy.
\end{abstract}

KEY WORDS: URINARY INCONTINENCE; IMPACT, QUALITY OF LIFE; PHYSIOTHERAPY.

\section{BACKGROUND}

Urinary incontinence remains an underreported and embarrassing condition across all countries and cultures, with severity directly related to decreased quality of life (Minassian, Drutz \& Al-Badr, 2003). Mason, Glenn, Walton and Appleton (1999) also suggest that the effects of urinary incontinence may vary according to the severity of the condition and the age of the woman. Psychological effects associated with this condition include depression, anxiety, irritability, worry, frustration and tension. The desire of affected patients to take part in recreational or sporting activities are also affected, as well as restriction of activities where toilet facilities are unknown (Mason et al, 1999). Apart from the feelings of embarrassment and anxiety, incontinence may negatively affect social participation, intimate relationships and self-esteem (Danforth et al, 2007). According to Mason et al (1999) urinary incontinence has a negative impact on sexual relationships. Studies suggest that urine leakage occurs during sexual activity in $12 \%$ of women, embedding a long term psychological impact (Barber, Dowsett, Mullen \& Viktrup, 2005).

Few women seek help for this condition and it has been reported that of those who consult, they tend to wait a long time after it has developed and most women find it difficult to talk about their condition (Mason et al, 1999). Although urine leakage affects the quality of life of sufferers, only a few women consult a healthcare professional. Unfortunately, physiotherapy is often overlooked by women with urinary incontinence, maybe because of their lack of knowledge/ awareness of the role physiotherapy in the management of this condition. At times, doctors prescribe medication for prolonged periods without referring these patients for physiotherapy. Pelvic floor exercises have been shown to be a safe and effective way of improving symptoms of urinary incontinence (Aksac, et al, 2003). Despite these proven benefits, Chiarelli et al, (2003) argues that lack of knowledge of benefits of these exercises leads to poor consultation and physiotherapy referral.

However, over the years, there has been an increase in the number of women who are referred for physiotherapy by their gynaecologists, presenting with some form of urinary incontinence, especially stress incontinence. Kapoor, Meher, Watkins and Das (2009), reported that among urogynaecology referrals, 38.9\% are for urinary incontinence, indicating the extent of the problem. More than a decade ago, Mantle and Versi (1991), reported that the majority of patients referred for physiotherapy, are referred by gynaecologists and more recently,

\footnotetext{
Corresponding Author:

Dr L Skaal

Department of Public Health

University of Limpopo

PO Box 1018

Medunsa

0204

E-mail: lskaal@ul.ac.za

Linda_Skaal@embanet.com
} 
Van Gerwen, Schellevis and LagroJanssen (2009) reported that only 20\% are referred by general practitioners. The aim of this study was to determine the prevalence of urinary incontinence, its impact on the quality of life, as well as physiotherapy consultation tendencies among the female staff at the University of Limpopo, South Africa.

\section{METHODS}

This was a quantitative, cross-sectional study, with a sample size of 145 females who were randomly selected from the female population of 336 obtained from the Human Resource Department at the University of Limpopo, Medunsa campus. A total of 152 female staff was approached and only 145 agreed to participate in the study. The sample size was determined using Raosoft sample size calculation where $n=N / 2.96=113$ and 32 was added to cater for nonresponse. The number for staff in each stratum (strata included academic staff, administrative staff and general workers) was calculated according to the total number of staff in each stratum. Prospective participants were selected from each stratum using a simple random sampling method. Informed consent was obtained from all identified participants. Participants were excluded if they were pregnant at the time of conducting the study. In addition, those who could not read/write were assisted by the researchers to complete the questionnaire. Before the main study, the questionnaire was piloted for face validity among 10 non-participating staff. The questionnaire was translated to SeTswana, to cater for those who did not understand English. Ethical clearance was obtained from the University Research Ethics Committee (MREC).

Three self-completed questionnaires were used to collect data and included the "Questionnaire for Urinary Diagnosis" (QUID), (Botlero et al, 2009) to determine diagnosis of UI; "Incontinence Impact Questionnaire” (IIQ-7) (Uebersax, Wyman, Shumaker, McClish, Fantl, $\&$ the Continence Program for Women Research Group, 1995), to determine the impact and "Incontinence Quality of Life" questionnaire (I-QoL), (Bushnell,
Martin, Summers, Svihra, Lionis\& Patrick, 2005) to determine the quality of life of those diagnosed with UI. In addition, the demographic data and anthropometric measurements and treatment options were also recorded. Data was analysed using the following scoring system, which has been previously validated by Botlero et al (2008).

QUID (Diagnosis): 5=Stress; 6-10 = Urge; $\geq 11=$ Mixed Incontinence

IIQ-7 ( Impact): Scores $7-9=$ Incontinence had an impact in their life.

IQOL ( Quality of life):Scores $\geq 10$ showed a decreased quality of life.

Responses were analysed and the peak incidences according to age and risk factors were recorded. SPSS 17.0 statistical tool was used to analyse the data and graphical and frequency tables, were used to present the data. Chi square was used to determine associations.

\section{RESULTS}

\section{Demographic Characteristics}

A total of 145 female staffs participated in the study, $53.8 \%$ were above and $46.2 \%$ were below 40 years of age. The majority of the participants (79.3\%) were black and $21 \%$ were white (Table 1 ).

The majority $(77.2 \%)$ of women were overweight (35.2\%) and obese (42.0\%) compared to only $22.8 \%$ of those with normal weight. In addition, $54 \%$ of the women reported that they did not exercise. According to race, a significant number of Blacks (80\%) were overweight/obese compared to $61.8 \%$ of whites $(\mathrm{p}=.005)$.

Most of the women had more than 2 deliveries and only $12.4 \%$ did not have children. In addition, $57.9 \%$ with children gave birth vaginally and $14.5 \%$ had both $\mathrm{C}$-section and vaginal deliveries. Of the participants, $24 \%$ of those who had children had episiotomies and $17 \%$ had hysterectomies. Most of the staff had hypertension (58.6\%), 19\% had diabetes mellitus, $16 \%$ were diagnosed with cancer and $6.9 \%$ had a heart disease.

Of the 46 women with urinary incontinence, 14 (30.4\%) scored more than 7 points on impact index, indicating that urinary incontinence had an impact in their quality of life. Also, $28 \%$ of women with urinary incontinence scored more than 11 on the quality of life index (QOL), indicating that they had decreased QOL. The majority of women with urinary incontinence $(86.9 \%)$ did not consult anybody for this problem and only $4.4 \%$ consulted health practitioners. Of those 6 women who consulted, 2 (33.3\%) received medication, $2(33.3 \%)$ surgery and $2(33.3 \%)$ were prescribed 'kegel

Table 1: The demographic characteristics of participants $(\mathrm{N}=145)$

\begin{tabular}{|l|l|l|l|}
\hline \multicolumn{2}{|l|}{ Variables } & N & $\%$ \\
\hline \multirow{3}{*}{ Age } & $<40 \mathrm{yrs}$ & 67 & 46.2 \\
\cline { 2 - 4 } & $\geq 40 \mathrm{yrs}$ & 78 & 53.8 \\
\hline \multirow{3}{*}{ Race } & Black & 115 & 79.3 \\
\cline { 2 - 4 } & White & 30 & 20.7 \\
\hline \multirow{3}{*}{ Occupation } & Lecturers & 37 & 25.5 \\
\cline { 2 - 4 } & Admin staff & 58 & 40 \\
\cline { 2 - 4 } & Service workers & 50 & 34.5 \\
\hline
\end{tabular}

Table 2: Body mass index and exercise history of participants ( $N=145)$

\begin{tabular}{|l|l|l|l|}
\hline \multicolumn{2}{|l|}{ Variables } & N & $\%$ \\
\hline \multirow{3}{*}{ BMI } & Norma; weight & 33 & 22.8 \\
\cline { 2 - 4 } & Overweight & 51 & 35.2 \\
\cline { 2 - 4 } & Obese & 61 & 42.0 \\
\hline \multirow{2}{*}{$\begin{array}{l}\text { Exercise (Do } \\
\text { you exercise?) }\end{array}$} & Yes & 66 & 45.4 \\
\cline { 2 - 4 } & No & 79 & 54.5 \\
\hline
\end{tabular}


exercises'. Reasons for not consulting a health professional are highlighted in Table 4.

The majority of women (97.8\%) diagnosed with urinary incontinence were not referred for physiotherapy. In addition, $95.7 \%$ did not know that physiotherapy can play a role and $89 \%$ did not know that physiotherapy exercises could help this problem.

\section{DISCUSSION}

Obesity has been reported to be one of risk factors associated to urinary incontince. Botlero et al (2009) and Luber (2004) also found that obesity was a significant risk factor for both stress and mixed incontinence. Khong and
Jackson (2008) also highlighted that urinary incontinence could be attributed to the accumulation of extra weight in the midsection, which may put pressure on the bladder. The results of this study revealed that approximately $42 \%$ of women were obese which poses a risk of developing urinary incontinence.

The results of this study demonstrated a high prevalence of hypertension $(58.6 \%)$ ), diabetes mellitus (19\%), cancer $(15.5 \%)$ and cardiac diseases $(6.9 \%)$ in the studies population. Barclay (2009) in his study on association between diabetes and urinary incontinence prevalence, found that $85 \%$ of subjects with diabetes had high prevalence of urinary incontinence. It is of concern that a high

Table 3: Cross-tabulation between variables and UI Prevalence ( $N=46)$

\begin{tabular}{|c|c|c|c|}
\hline \multicolumn{2}{|l|}{ Variables } & \multirow{2}{*}{$\begin{array}{l}\text { UI Prevalence } \\
\text { n (\%) } \\
22(47.8)\end{array}$} & \multirow{2}{*}{ P-value } \\
\hline \multirow[t]{2}{*}{ Age } & $<40 y r s$ & & \\
\hline & $\geq 40 \mathrm{yrs}$ & $24(52.2)$ & .464 \\
\hline \multirow[t]{3}{*}{ Job Category } & Lecturers & $8(17.4)$ & \multirow{3}{*}{.174} \\
\hline & Admin staff & $20(43.5)$ & \\
\hline & General workers & $18(39.1)$ & \\
\hline \multirow[t]{2}{*}{ Race } & Blacks & $31(67.4)$ & \multirow[b]{2}{*}{.041} \\
\hline & Whites & $15(32.6)$ & \\
\hline \multirow[t]{3}{*}{ BMI } & Normal weight & 5 (10.9) & \multirow{3}{*}{.010} \\
\hline & Overweight & $16(34.8)$ & \\
\hline & Obese & $25(54.3)$ & \\
\hline \multirow[t]{2}{*}{ Exercise } & Exercise & $20(43.5)$ & \multirow[b]{2}{*}{.438} \\
\hline & No exercise & $26(56.5)$ & \\
\hline \multirow{4}{*}{$\begin{array}{l}\text { Delivery } \\
\text { method }\end{array}$} & Normal & $29(63.0)$ & \multirow{4}{*}{.601} \\
\hline & Caesarean Section & $6(13)$ & \\
\hline & Mixed & $4(8.7)$ & \\
\hline & No child & 7 (15.3) & \\
\hline
\end{tabular}

Table 4: Reasons for not seeking medical intervention ( $N=46)$

\begin{tabular}{|l|l|l|}
\hline Reasons for not consulting & $\mathbf{n}$ & $\%$ \\
\hline Not serious problem & 14 & 35 \\
\hline Embarrassed & 2 & 5 \\
\hline It's natural & 8 & 20 \\
\hline Fear to consult & 1 & 2.5 \\
\hline No time & 8 & 20 \\
\hline Not going to toilet & 3 & 7.5 \\
\hline Did not specify & 4 & 10 \\
\hline
\end{tabular}

number of young participants in this study suffer from urinary incontinence. The results of the study showed there was no significant difference between urinary incontinence prevalence and age $(p=.464)$. This was in contrast to the findings by Nitti (2001) which showed that the prevalence of urinary incontinence is low among young women and peak post menopause and at older ages. Botleroet al (2009) found that the peak incidence of stress and urge incontinence peaked in the ages over 40yrs. The findings of this study differ with findings of Nitti (2001) and Botlero et al (2009), and may imply that these 2 types of urinary incontinence are more prevalent across all age groups. Therefore, awareness interventions should be started as early as 20 years in this population.

In the current study black women $(67.4 \%)$ had a significantly higher prevalence of urinary incontinence compared to white women $(32.6 \%, \mathrm{p}=.041)$. In contrast, Thom et al (2006), found urinary incontinence to be more prevalent in white women than in black women. Newman (2001) and Thom et al (2006) also reported that white women are more at risk of urinary incontinence because anatomically, they have a shorter urethra, weaker pelvic floor muscles, and a lower bladder neck than black women, thus making them more likely to have incontinence. It is not clear whether these physiological differences are present in the subjects of this study, and the difference in outcome can thus not be explained. The results of the current study imply that black women are vulnerable group to a higher prevalence of urinary incontinence, possibly due to increased obesity in this race.

Kim, McEwen, Sarma, Piette \& Herman (2008) found that urinary incontinence affected activities after delivery more frequently among women who were less educated and that higher levels of education and income were associated with low levels of incontinence. In a study done on Chinese women by Wong, Lau, Mak, Pang, Cheon and Yip (2006), the results showed that $78 \%$ of respondents did not know that urinary incontinence is a disease entity, but for those who sought treatment, physiotherapy was their first 
choice of treatment. The fact that the majority of staff who exercise were lecturers, compared to general staff, could be the reason why lecturers have lower levels of urinary incontinence. Danforth et al (2007) also did a study on effects of physical activity on urinary incontinence and found that increasing levels of physical activity were significantly associated with reduced risk of urinary incontinence. About $30 \%$ of women reported that urinary incontinence had a negative impact and also a decreased quality of life. Minassian et al (2003) also found that $50 \%$ of women with incontinence reported that urinary incontinence affected their quality of life.

An overwhelming $87 \%$ of women with urinary incontinence did not seek professional help. This is consistent with the study by Mason et al (1999) who stated that few women seek help for urinary incontinence. Minassian et al (2003) reported that despite $50 \%$ of the participants reporting that the leakage of urine affected their quality of life, an overwhelming 93\% did not seek help. Even with severe incontinence, only $42.5 \%$ consulted a healthcare professional. This study's findings are also consistent with Luber (2004) who suggested that reasons for not consulting can be related to embarrassment to talk about the condition or fear that treatment may require surgery. In the current study, only $4 \%$ of the women knew the physiotherapists' role in this condition, with $13 \%$ knowing that there are exercises to treat this condition. This is in contrast with Wong et al (2006) who found that majority of subjects in his study consulted a physiotherapist.

\section{CONCLUSION}

There is a significant prevalence of urinary incontinence among the females in the studied population, with a significant impact on their quality of life. The majority of participants did not know the significant role of physiotherapy in managing this problem. It is therefore recommended that physiotherapists take the initiative in empowering women in general about the existing treatment options that do not involve surgery. A holistic approach should be empha- sized in all high risk women, in order to identify those at risk and educate about the existence of urinary incontinence and the treatment thereof. An extensive health promotion intervention need to be done by physiotherapists to raise awareness, empower people and educate both the community and the professional colleagues about the role of physiotherapists so that there will be future referrals and patients can get the first-line, low-cost and effective treatment that is provided by physiotherapists.

\section{Limitations of this study}

Limitations of this study are that the selfreported leakage of urine questionnaire QUID does not include frequency of leakage and severity of leakage, which may lead to misdiagnosis and participants may feel that symptoms do not translate into a level of 'bother' that qualifies the condition of Urinary Incontinence. The researcher thus recommends that further studies utilize the validated tool: "Severity Index" by Hanley, Capewell, Hagen (2001) to further classify urinary incontinence into levels of severity and amount of urine loss.

\section{Implications of this study}

Urinary incontinence is a big health problem, with psychological impact that affects women of all agegroups, and race. Because of its presentation, women continue to treat UI as a closet problem. UI has an impact on quality of life of women, especially of middle age group. UI poses a public health challenge to all physiotherapists to engage in awareness campaigns so as to change perceptions; improve knowledge and empower women to seek early intervention such as physiotherapy for this problem.

\section{REFERENCES}

Aksac B, Aki S, Karan A, Yalcin O, Isikoglu M, Eskiyurt N 2003 Biofeedback pelvic floor exercises for rehabilitation of urinary stress incontinence. Gynecology\& Obstetrics Invest 56(1):23-27

Barber MD, Dowsett SA, Mullen KJ, Viktrup L 2005 The impact of stress urinary incontinence on sexual activity in women. Cleveland Clinic Journal of Medicine 72(3):225-232
Barclay L 2009 Urinary Incontinence Highly prevalent in overweight, obese women with type 2 Diabetes. New England Journal of Medicine 29:481-490

Botlero R, Davis SR, Urquhart DM, Shortreed S, Bell RJ 2009 Age-specific prevalence of, and factors associated with, different types of urinary incontinence in community-dwelling Australian women assessed with a validated questionnaire. Maturitas 62(2):134-139

Botlero R, Urquhart DM, Davis SR, Bell RJ 2008 Prevalence and incidence of urinary incontinence in women: review of the literature and investigation of methodological issues. International Journal of Urology15:230-234.

Bushnell DM, Martin ML, Summers KH, Svihra J, Lionis C, Patrick DL 2005 Quality of life of women with urinary incontinence: Crosscultural performance of 15 language versions of the I-QOL. Quality of Life Research, Springer 14:1901-1913

Chiarelli P, Murphy B, Cockburn J 2003 Women's knowledge, practises intentions regarding correct pelvic floor exercises. 22(3):246-249

Danforth KN, Shah AD, Townsend MK, Lifford KL, Curhan GC, Resnick NM, Grodstein F 2007 Physical Activity and Urinary Incontinence among healthy older women. Obstets Gynaecol 109(3):721-727.

Danforth KN, Towsend MK, Lifford K, Curhan GC, Resnick NM, Goldstein F 2006 Risk factors for urinary incontinence among middleaged women. American Journal of Obstetrics Gynecology 194:339-345

Hanley J, Capewell A, Hagen S 2001 Validity study of the severity index, a simple measure of urinary incontinence in women. British Medical Journal 322(7294):1096 - 1097

Kapoor DS, Meher S, Watkins L, Das H 2009 Referral patterns for pelvic floor disorders. International Urogynecology Journal of Pelvic Floor Dysfunction 20(12):1469-1472

Khong S, Jackson S 2008 Obesity and Urinary Incontinence. Menopause International 14(2):53-56

Kim C, McEwen LN, Sarma AV, Piette JD, Herman WH 2008 Stress Urinary Incontinence in Women with a History of Gestational Diabettes Mellitus. Journal of Women's Health 17(5): 783-792

Luber L 2004 The Definition, Prevalence, and Risk Factors for Stress Urinary Incontinence. Reviews in Urology 6(3):S3-S9

Mantle J, Versi E 1991 Physiotherapy for stress urinary incontinence: a national survey. British Medical Journal 302(6779):753 -755 
Mason L, Glenn S, Walton I, Appleton C 1999 The Experience of Stress Incontinence After Childbirth. Birth 26(3):164-171

Minassian VA, Drutz HP, Al-Badr A 2003 Urinary Incontinence as a worldwide problem.International Journal of Gynaecology and Obstetrics 82(3):327-338

Newman DK 2001 Conservative Management of Urinary Incontinence in women. Prim Care Update Obsterics and Gynaecology 8(4)153-162.

Nitti VW 2001 The prevalence of Urinary Incontinence. Reviews in Urology 3(1):S2-S6

Stach-Limpinen B, Nygard C, Laippala P, Metsanoja R, Kujansuu E 2004 Is physical activity influenced by Urinary Incontinence? International Journal of Obstetrics\& Gynaecology. 111:475-480

Thom DH, Van Den Eeden SK, Ragins AI, Wassel-Fyr C, Vittinghof E, Subak LL, Brown JS 2006 Differences in Prevalence of Urinary Incontinence by Race/ Ethnicity. Journal of Urology 175(1):259-264

Uebersax JS, Wyman JF, Shumaker SA, McClish DK, Fantl JA 1995 The Continence Program for Women Research Group. Neurology and Urodynamics Journal 14: 131-139.

Van Gerwen MA, Schellevis FG, LagroJanssen AL 2009 Management of urinary incontinence in general practice: data from the Second Dutch National Survey. Journal of Evaluation in Clinical Practice 15(2):341-345

Wong T, Lau BY, Mak H, Pang M, Cheon C, Yip S 2006 Changing prevalence knowledge of Urinary Incontinence among Hong Kong Chinese Women. International Uro-gynaecology Journal 17(6):593-597 